\title{
BMJ Global Health Local ownership of health policy and systems research in low-income and middle-income countries: a missing element in the uptake debate
}

\author{
Kudakwashe Paul Vanyoro, ${ }^{\oplus 1}$ Kate Hawkins, ${ }^{2}$ Matthew Greenall, ${ }^{3}$ Helen Parry, ${ }^{3}$ \\ Lynda Keeru ${ }^{4}$
}

To cite: Vanyoro KP, Hawkins K, Greenall M, et al. Local ownership of health policy and systems research in low-income and middle-income countries: a missing element in the uptake debate. BMJ Global Health 2019;4:e001523. doi:10.1136/ bmjgh-2019-001523

Handling editor Stephanie M Topp

Received 20 February 2019

Revised 18 June 2019

Accepted 5 July 2019

Check for updates

(c) Author(s) (or their employer(s)) 2019. Re-use permitted under CC BY-NC. No commercial re-use. See rights and permissions. Published by BMJ.

${ }^{1}$ African Centre for Migration \& Society, University of the Witwatersrand School of Social Sciences, Johannesburg, South Africa

${ }^{2}$ Pamoja Communications, Brighton, UK

${ }^{3}$ Independent consultant, Brighton, UK

${ }^{4}$ LVCT Health, Nairobi, Kenya

Correspondence to Kudakwashe Paul Vanyoro; kudakwashe.vanyoro@wits. ac.za

\section{ABSTRACT}

Health policy and systems researchers (HPSRs) in lowincome and middle-income countries (LMICS) aim to influence health systems planning, costing, policy and implementation. Yet, there is still much that we do not know about the types of health systems evidence that are most compelling and impactful to policymakers and community groups, the factors that facilitate the research to decision-making process and the real-world challenges faced when translating research findings into practice in different contexts. Drawing on an analysis of HPSR from LMICs presented at the Fifth Global Symposium on Health Systems Research (HSR 2018), we argue that while there is a recognition in policy studies more broadly about the role of co-production, collective ownership and the value of localised HPSR in the evidence-to-policy discussion, 'ownership' of research at country level is a research uptake catalyst that needs to be further emphasised, particularly in the HPSR context. We consider embedded research, participatory or community-initiated research and emergent/responsive research processes, all of which are 'owned' by policymakers, healthcare practitioners/ managers or community members. We embrace the view that ownership of HPSR by people directly affected by health problems connects research and decision-making in a tangible way, creating pathways to impact.

\section{INTRODUCTION}

Health policy and systems researchers (HPSRs) in low-income and middle-income countries (LMICs) investigate how health systems can be better organised to encourage health access, uptake, equity and coverage and to achieve greater overall impact. They aim to influence health systems planning, costing, policy and implementation. ${ }^{1}$ Yet, we do not know much about the types of health systems evidence that are most compelling and impactful to policymakers and community groups, factors that facilitate the research to decision-making process and real-world

\section{Summary box}

Three theoretical domains guide models designed to overcome the barriers to research uptake: (1) conceptualising types of policy and practice change; (2) understanding the decision-making environment and (3) actions taken to encourage evidence use.

- There is a recognition in policy studies more broadly about the role of co-production, collective ownership and the value of localised health policy and systems research (HPSR) in the evidence-to-policy discussion.

- 'Ownership' of HPSR at country level is a research uptake catalyst that needs to be further emphasised, particularly in the HPSR context.

- Ownership of HPSR by people directly affected by health problems connects research and decision-making in a tangible way, creating pathways to impact.

- The types of ownership identified include embedded research, participatory or community-initiated research and emergent/responsive research processes, all of which are 'owned' and often initiated by policymakers, healthcare practitioners/managers or community members.

- There are lessons from these approaches that could support strengthened theorising within the field of research communications more generally to enable or foster 'bottom up' efforts by communities, local policymakers and practitioners.

challenges faced when translating research findings into practice in different contexts.

Drawing on an analysis of health policy and systems research (HPSR) from LMICs presented at the Fifth Global Symposium on Health Systems Research (HSR 2018), we argue that while there is a recognition in policy studies more broadly about the role of co-production, ${ }^{2-4}$ collective ownership and the value of localised HPSR in the evidenceto-policy discussion, ${ }^{5}$ 'ownership' of research at country level is a research uptake catalyst 
that needs to be further emphasised, particularly in the HPSR context. Here we understand ownership to mean the process whereby co-production enables health system actors (from policymakers to service users) to determine and influence research agendas with direct engagement with the research process itself. ${ }^{5}$

We attended HSR 2018 to identify, collate and analyse examples of policy and systems research impact as well as factors affecting research and evidence use in the health systems and policy arena. We reviewed the programme to identify poster and oral presentation sessions of potential interest for our topic and documented them by taking notes into a predeveloped proforma. Where possible, we made direct contact with presenters after the sessions requesting them to share presentations and any additional documentation or papers. These notes were reviewed and thematically coded.

In the analysis, we selected sessions whose descriptions referred to key themes such as getting research into policy and practice, research uptake, policy influence, embedded research, implementation science and timely evaluation in LMICs and fragile and conflict-affected settings. We reviewed the initial selection of sessions and refined the choices made to a final set of 77 sessions that would be documented during the conference. We coded the data according to the following themes: 'embedded', 'research uptake strategy', 'system-wide policy', 'ad hoc or emergent data use', 'scale up', 'capacity building', 'communities of practice', 'participatory research' and 'barriers to research uptake'. This analysis was supplemented by an exploration of theoretical and empirical literature on the topic of evidence-to-policy processes. Theoretical and empirical literature was gathered from resources including the Wits University online library catalogue and Google Scholar.

We begin by briefly outlining the prominent debates on research and evidence uptake. Then we outline prominent theories that explain policy and practice change from this review. Three types of 'ownership' we identified are then outlined: (1) embedded research; (2) participatory or community-initiated research and (3) emergent/ responsive research processes. This outline is complemented by a discussion of selected cases we documented at HSR 2018 that relate to how each type of 'ownership' has been operationalised by HPSRs in LMIC contexts.

\section{PROMINENT DEBATES ON RESEARCH AND EVIDENCE UPTAKE}

Research has an important role to play in strengthening health system performance and public health. ${ }^{6}$ Policymaking processes are not well understood, including among HPSRs who wish to see their research have a stronger influence. ${ }^{7-9}$ We know little about the mechanisms of policy change in LMICs, and there is a particular gap in evidence from 'difficult' environments, such as post-conflict and fragile settings. Use of evidence in decision-making may be more challenging and less institutionalised, involving a multiplicity of stakeholders with diverse interests, and complex and fluctuating governance arrangements for policymaking. ${ }^{9-12}$

Our review of literature exploring evidence-to-policy processes suggests that there are three main theoretical domains that guide models designed to overcome the barriers to research uptake: (1) conceptualising types of policy and practice change ${ }^{13-19}$; (2) understanding the decision-making environment ${ }^{720-26}$ and (3) actions taken to encourage evidence use (including knowledge translation, knowledge brokering and research uptake). $.^{23} 27-34$

It is recognised that embedded and participatory research can help facilitate the use of evidence by making data more relevant to real-world challenges. ${ }^{1535-38}$ While there is growing emphasis on how co-production can inform our understanding of research uptake and the potential benefits of being 'ownership-oriented' within research efforts, ${ }^{2-4}$ this is less so in HPSR contexts and when it comes to emergent/responsive research.

\section{PROMINENT THEORIES TO EXPLAIN POLICY AND PRACTICE CHANGE}

Policy and policy processes are contested, involving multiple actors, with different concerns, interests and values, and are influenced by a range of contextual factors. ${ }^{3940}$ Contemporary models to explain evidence use increasingly challenge traditional assumptions that view research uptake and policymaking as linear processes where the end point is the uptake of evidence into written documents. There is consensus that the types of influence that research might have on decision-making are not necessarily instrumental and that research may also have a conceptual use ${ }^{17-1940}$ or an 'enlightenment function'. 131439

The literature states that researchers and practitioners of evidence-based decision-making should address the 'human factor' in the context of research uptake, which mainly concerns issues of power, actors and context. ${ }^{20} 21$ It is suggested that to be effective influencers, they need a sophisticated understanding of policymaker psychology and the role of factors such as group dynamics and the rules that people follow within organisations. ${ }^{23}$ Policy narratives, ${ }^{23}$ democratic openness, technical ability to take up evidence, ${ }^{24}$ institutional arrangements, policy windows $^{2526}$ and levels of decentralisation are all identified as affecting the process.

It is argued that those wishing to influence policy and practice may face a number of barriers characterised as systemic, institutional and individual. Systemic barriers identified include the differing timelines of research and decision-making processes, a lack of knowledge among researchers about how decisions are made, the distorting impact of funders on decision-making, poor communication skills among researchers and misaligned incentives between the research and policy worlds. ${ }^{28} \mathrm{At}$ the institutional level, research organisations may not have adequate infrastructure (staff, dedicated teams) to 
communicate their work, which in addition may not be appropriately funded, particularly in LMICs. ${ }^{28}$

Davidson provides a useful typology of the different ways policymakers can be influenced, arguing that interventions can take place on an 'inside track' or 'outside track' and can take place formally or informally within each of these tracks. ${ }^{23}$ The inside track entails cooperative relationships between scientific researchers, allies and policymakers (through meetings, negotiations and in-person discussion). ${ }^{23}$ The 'outside track', 'may be more confrontational and often entails influencing decision-makers indirectly through public pressure' (13, p $3)$. Informally, this takes the form of activism, or more formally, it takes the shape of advocacy.

\section{PRACTITIONER AND COMMUNITY OWNERSHIP OF THE EVIDENCE}

The three theoretical domains of evidence uptake presented above relate to the different types of research/ evidence, capacities and institutional arrangements needed to address different steps in the policy or decision-making process. They focus on strategies of making and strengthening links between researchers and policymakers. ${ }^{36}$

Our review suggests that these theories do not pay sufficient attention to the role of ownership. They focus on the role of researchers or dedicated knowledge management or communications staff in brokering relationships with policymakers. Our analysis of embedded research, community-initiated and participatory research, emergent/responsive research together with Davidson's typology on the inside and outside track demonstrates how ownership is a concept that should be applied not only to the findings of research. Rather, ownership of the research focus, process and outcomes is key to promoting uptake and consequently needs to be better integrated into models of knowledge generation and use.

\section{Ownership by healthcare practitioners and managers: embedded research}

One mechanism for ensuring that links are made between HPSRs and research users is embedded research. ${ }^{1535-38}$ It generally follows the inside track ${ }^{23}$ as it entails HPSRs working 'in direct interface with the constituency they serve' (1, p 958). Locally designed and driven research is key to ensuring that health services and delivery processes are more relevant to contextually specific challenges and also increase local ownership of new programmes and drive translation from research into practice. ${ }^{553738}$ While there are various models and definitions of embedded research, they tend to be guided by similar underlying principles and steps. ${ }^{35}$ They are driven by contextually relevant questions constructed through partnerships with local health system actors.

Embedded approaches seek to generate data and evidence for use in real time rather than to fulfil other research incentives, ${ }^{41}$ although the research may not always be used in real time. They aim to create learning systems and an architecture within which data collection, quality and use are prioritised. These might include platforms or regular meetings to discuss data and priorities. ${ }^{5}$ Within embedded research, HPSRs tend to take an insider position, working alongside and in partnership with their health system peers to co-produce knowledge. ${ }^{53542}$ Embedded research can also be driven from the outside, even if it ultimately takes shape inside the system.

There is vast evidence of embedded research influencing changes in service delivery and health outcomes in LMICs. For example, embedded research from the Beira Operations Research Center in the Mozambique Population Health Implementation and Training Partnership aimed to improve the quality and use of routine health system data within the health information system through audit and feedback approaches. ${ }^{43} 44$ As a result, concordance of data (ie, filling out data according to given categories) improved from $54 \%$ to $89 \%$, and the incidence of stock-outs of essential medicines within facilities reduced. ${ }^{44}$ The Integrated District Evidence to Action project based at the Centre focused on reducing neonatal mortality by improving health system capacity to deliver a package of evidence-based interventions delivered at or around the time of birth in 12 districts, using an embedded research approach. Led by district management teams, the approach was cyclical and iterative. It incorporated facility and district readiness assessments; district performance reviews and targeted facility support for use of data. The initiative institutionalised embedded research through capacity building, research training and implementation research. ${ }^{44}$

HPSRs from KEMRI Wellcome Trust at RESYST learning sites worked in Kilifi County, Kenya-a longstanding collaboration between HPSRs and managers for facilitating real-time research uptake for system strengthening in the process of political devolution. ${ }^{645} 46$ The overall aim of the project was to nurture every day resilience among healthcare staff. ${ }^{15}$ In spite of ethical challenges, ${ }^{646}$ an embedded approach led to changes in policy such as a county law, which provides control to hospital managers in managing income derived from user fees. ${ }^{45}$ The approach was determined through the creation of research questions with practitioners, which led to a systematised process of planning, implementation and reflection around activities considered most important. ${ }^{6} 4546$

\section{Responsive/emergent identification and use of evidence}

Theories of how evidence is used in practice tend to emphasise formalised approaches to evidence uptake. However, not all evidence use in LMICs is planned or systematic: sometimes evidence is used in a 'responsive' or 'emergent' way. The ability of health actors and decision-makers-particularly at local level-to identify, collect and interpret evidence in response to new or emerging challenges is an important feature of 
resilient, responsive health systems ${ }^{47}$ and a key tenet of 'people-centredness'. ${ }^{48}$

The recent Ebola crisis in West Africa 'highlights how an epidemic can proliferate rapidly and pose huge problems in the absence of a strong health system capable of a rapid and integrated response' (35, p 850). However, it also provides examples of responsive data generation and use. It illustrates that for health programmes to be evidence based, it is not enough to simply address the biological mechanisms or focus solely on reducing transmission and the effect of the disease, ${ }^{49}$ in what appears to be the quickest and most reliable way. ${ }^{50}$ Ebola finally came under control using largely the same basic mechanisms that had been employed in the initial response, but the difference was that the evidence on how to control Ebola had to be operationalised based on evidence of how to effectively apply those measures in context. ${ }^{50}$ Local decision-makers relied on local data to shape their response through collection of case reports, interviewing of patients and family members, coordination of contact tracing and consolidation of data into centralised databases. ${ }^{51}$ Effective application of Ebola control was based on adaptation, negotiation and responsiveness by local health decision-makers, leaders and communities. ${ }^{50}$

Emergent data use can also take the form of learning at the service delivery level. Two examples from the tuberculosis (TB) response in South Africa illustrate this. As drug-resistant forms spread, despite the existence of a decentralisation policy, there was limited transfer of responsibility to the service provision level and limited resources, support or guidance for implementation of the policy. Many service providers did not know how to operationalise implementation guidelines. Providers were forced to seek out and generate evidence to support the changes they needed to decentralise TB treatment. ${ }^{52}$ They engaged, out of necessity, in 'decentralised' policy-making, self-organisation, learning and adaptation, with their local discretion and knowledge to challenge linear understanding of interventions leading to the emergence of contextually appropriate approaches. ${ }^{52}$ This ability to adapt, self-organise and learn-'tinkering'-included looking up and adapting research on models implemented in other countries, or used for treating other conditions (such as HIV), as well as directly conducting impromptu small-scale research. Although sometimes this research was informal and based on the sharing of small-sample observations between practitioners, it became seen as authoritative evidence within local contexts. ${ }^{52}$

\section{Ownership by members of vulnerable or excluded groups: participatory, community-initiated research}

There are compelling examples of health systems evidence use in LMICs that is either led by or actively engages with vulnerable or excluded groups. Rather than fitting the usual model of research production and dissemination, these approaches take the principle of ownership and engagement by excluded groups as the starting point for policy or programme change, following the outside track. ${ }^{23}$ Participatory or community-initiated research is often born out of necessity. HPSRs are not always well placed to be embedded in local contexts because they may not know how to address the 'thorny issue' of the boundary between researcher and advocate. ${ }^{553}$

Health services in most countries aim to be universally available but some groups remain systematically excluded, because of factors that include remoteness, mobility, ethnic or cultural differences or discrimination. For example, reasons for exclusion of Roma and indigenous populations were complex but typically included discrimination which stems from social, cultural and political norms, gender inequalities and a lack of tailored or targeted services. ${ }^{545}$

Significantly, for these groups, systematic exclusion from health services is mirrored by exclusion from health data. ${ }^{5657}$ Many health information systems and research initiatives either do not have data of good enough quality or do not conduct the disaggregated analysis that would shine a light on inequalities and exclusions in health service access or health outcomes. ${ }^{58}$ Compounding this is the fact that excluded groups are often unaware of their rights and not well positioned to demand better provision from the state. The lack of disaggregated data, or of collection of variables related to ethnicity or information on non-nationals in official statistics, often indicates that exclusion has a political dimension. This can result in the reluctance of excluded groups to engage with authorities that they have reasons not to trust.

We found many examples at HSR 2018 of research or data collection that originated within excluded groups and led to policy change or other action in LMICs. These included the Roma population in Macedonia, indigenous women living in remote areas in Peru and adolescent girls and young women in India conducting and reporting surveys and qualitative research in order first to educate themselves about their rights, and second to demand better services from authorities. ${ }^{58}$

Another example from Guatemala included participatory approaches such as the collection of evidence of human rights violations using video cameras and establishing complaints platforms for social accountability. ${ }^{59} \mathrm{~A}$ further example, from Nigeria, described an approach to addressing exclusion through national health budget analysis, linking non-disbursement of committed funding to programmatic data showing segments of the population being left behind by key health services. ${ }^{54}$ In the budget analysis example from Nigeria, the research was just a first step in a 5-year process of mobilising support from community associations, non-governmental organisations and members of parliament, which eventually contributed to improved legislation on budgetary allocations to health.

A similar example of civil society-led budget monitoring was provided by the Malawi Health Equity Network, which contributed to campaigns with members of parliament, key cabinet ministers and other actors resulting 
in steady increases in health budgets and realisation by communities about their right to be heard on issues of health. ${ }^{60}{ }^{61}$ Participatory, qualitative research aimed at driving increased attention to identifying and addressing gender biases in the health workforce was also highlighted in a number of cases.

\section{CONCLUSION}

Debates on research and evidence uptake that focus on ensuring that links are made and strengthened between researchers and policymakers underexplore the role and processes of ownership. They neglect the strategies that communities and health practitioners develop when they need to respond to emerging issues, which often involve seeking out and using their own evidence.

While these approaches are important, they are certainly not the only or most appropriate way to strengthen research uptake. Some topics that are particularly sensitive may require an independent research group to own the research process to ensure that politically sensitive results can still be published. Highly embedded forms of HPSR also present unique ethical challenges. ${ }^{6}{ }^{4}$

This paper highlights the potential of recognising and adopting 'ownership-oriented' approaches to support research uptake efforts at country level. Our analysis is consistent with evidence showing that 'joint ownership' of research facilitates the integration of scientific findings in policy implementation and health systems strengthening. We embrace the view that ownership of HPSR by healthcare practitioners and managers and members of vulnerable or excluded groups is an important factor in connecting research and policymaking in a tangible way, with clear pathways that result in tangible benefits for intended policy beneficiaries. These approaches are being adopted in the health systems research world to positive effect. They provide lessons that could support strengthened theorising within the field of research communications to enable or foster 'bottom up' efforts by communities, local policymakers and practitioners, thus contributing to achievement of the health-related SDGs.

\section{Acknowledgements We acknowledge the Liverpool School of Tropical Medicine for funding this study and the Secretariat of Health Systems Global for their support to the research. Time for KH's conceptual review, editing and responding to reviewers' comments was funded through Global Challenges Research Fund (GCRF) Accountability and Responsiveness in Informal Settlements for Equity Hub (ARISE) RC Grant reference: ES/S00811X/1.}

Contributors KV, KH, MG, HP and LK conceived the presented idea. KV developed the theory. HP and LK verified the analysis and supervised the quality of the findings of this work. All authors discussed the results and contributed to the final manuscript.

Funding The authors have not declared a specific grant for this research from any funding agency in the public, commercial or not-for-profit sectors.

Competing interests None declared.

Patient consent for publication Not required.

Provenance and peer review Not commissioned; externally peer reviewed.

Data availability statement No additional data are available.
Open access This is an open access article distributed in accordance with the Creative Commons Attribution Non Commercial (CC BY-NC 4.0) license, which permits others to distribute, remix, adapt, build upon this work non-commercially, and license their derivative works on different terms, provided the original work is properly cited, appropriate credit is given, any changes made indicated, and the use is non-commercial. See: http://creativecommons.org/licenses/by-nc/4.0/.

\section{REFERENCES}

1. World Health Organisation. Changing mindsets: strategy on health policy and systems research. Geneva: World Health Organisation, 2012.

2. Cairney P, Oliver K. Evidence-Based policymaking is not like evidence-based medicine, so how far should you go to bridge the divide between evidence and policy? Health Res Policy Syst 2017;15.

3. Evans S, Scarbrough H. Supporting knowledge translation through collaborative translational research initiatives: 'bridging' versus 'blurring' boundary-spanning approaches in the UK CLAHRC initiative. Soc Sci Med 2014;106:119-27.

4. Hinchcliff R, Greenfield D, Braithwaite J. Is it worth engaging in multi-stakeholder health services research collaborations? reflections on key benefits, challenges and enabling mechanisms. Int J Qual Health Care 2014;26:124-8.

5. Lehmann U, Gilson L. Action learning for health system governance: the reward and challenge of co-production. Health Policy Plan 2015;30:957-63.

6. Molyneux S, Tsofa B, Barasa E, et al. Research involving health providers and managers: ethical issues faced by researchers conducting diverse health policy and systems research in Kenya. Dev World Bioeth 2016;16:168-77.

7. Andrews L. How can we demonstrate the public value of evidencebased policy making when government ministers declare that the people 'have had enough of experts'? Palgrave Commun 2017;3.

8. Bissell K, Viney K, Brostrom R, et al. Building operational research capacity in the Pacific. Public Health Action 2014;4(Suppl 1):2-13.

9. Malla C, Aylward P, Ward P. Knowledge translation for public health in low- and middle- income countries: a critical interpretive synthesis. Glob Health Res Policy 2018;3.

10. Hawkins K, Health Systems Global. How to get health systems evidence into policy and practice in fragile and conflict-affected settings. Available: https://www.healthsystemsglobal.org/blog/192/ How-to-get-health-systems-evidence-into-policy-and-practice-infragile-and-conflict-affected-settings.html [Accessed 18 Feb 2019].

11. Sanderson I. Complexity, "practical rationality" and evidence-based policy making, 2006. Available: https://www.ingentaconnect.com/ content/tpp/pap/2006/00000034/00000001/art00007 [Accessed 10 Apr 2019].

12. Cairney P. Complexity theory in political science and public policy. Political Studies Review 2012;10:346-58.

13. Weiss CH. Research for Policy's Sake: The Enlightenment Function of Social Research. Policy Analysis 1977;3:531-45.

14. Weiss $\mathrm{CH}$. The many meanings of research utilization. Public Adm Rev 1979;39:426-31.

15. Gilson L, Mclntyre D. The interface between research and policy: experience from South Africa. Soc Sci Med 2008;67:748-59.

16. Boswell C, Smith K. Rethinking policy 'impact': four models of research-policy relations. Palgrave Commun 2017;3.

17. Young J, Mendizabal E. Helping researchers become policy entrepreneurs [Internet]. London: ODI, 2009. Available: https://www. odi.org/publications/1127-helping-researchers-become-policyentrepreneurs [Accessed 18 Feb 2019].

18. Jones N, Sumner A. Child poverty, evidence and policy [Internet]. Bristol: Policy Press, 2011. Available: https://www.press.uchicago. edu/ucp/books/book/distributed/C/bo13436643.html [Accessed 18 Feb 2019].

19. Jones $\mathrm{H}$. A guide to monitoring and evaluating policy influence [Internet]. London: ODI, 2011. Available: https://www.odi.org/ publications/5252-guide-monitoring-and-evaluating-policy-influence [Accessed 18 Feb 2019].

20. Oliver K, Pearce W. Three lessons from evidence-based medicine and policy: increase transparency, balance inputs and understand power. Palgrave Commun 2017;3.

21. Vanyoro KP. Pragmatic Pathways: Critical Perspectives on Research Uptake in the Global South [Internet]. Brighton, UK: Migrating out of Poverty Consortium, University of Sussex; (Migrating out of Poverty RPC Working Paper No. 30), 2015. Available: https://www.gov.uk/ dfid-research-outputs/pragmatic-pathways-critical-perspectives-on- 
research-uptake-in-the-global-south-migrating-out-of-poverty-rpcworking-paper-no-30\#citation

22. Grimm K. Mindful messaging. Available: http://mindfulmessaging. spitfirestrategies.com/wp-content/uploads/2016/11/MindfulMessaging-print2.pdf

23. Davidson B. Storytelling and evidence-based policy: lessons from the grey literature. Palgrave Commun 2017;3.

24. Varallyay I. Theory of change for enhancing the capacity of decisionmakers to use research evidence, 2018. Available: http://www.who. int/alliance-hpsr/callsforproposals/HIGH-Res-call-1-2.pdf?ua=1

25. Cairney P, Kwiatkowski R. How to communicate effectively with policymakers: combine insights from psychology and policy studies. Palgrave Commun 2017;3.

26. Agendas KJW. Alternatives, and public policies. Pearson: Essex, 2014

27. Delany-Moretlwe S, Stadler J, Mayaud P, et al. Investing in the future: lessons learnt from communicating the results of HSV/ HIV intervention trials in South Africa. Health Res Policy Syst 2011;9.

28. Knezovich J. The challenges of research uptake: systemic, institutional and individual barriers. Available: http://www. futurehealthsystems.org/blog/2012/12/17/the-challenges-ofresearch-uptake-systemic-institutional-and.html [Accessed 18 Feb 2019].

29. Crichton J, Theobald S. Strategies and tensions in communicating research on sexual and reproductive health, HIV and AIDS: a qualitative study of the experiences of researchers and communications staff. Health Res Policy Sys 2011;9(S1).

30. Shaxson L, Bielak AT. Expanding our understanding of $\mathrm{K}^{*}(\mathrm{KT}$, ke, $\mathrm{KTT}, \mathrm{KMb}, \mathrm{KB}, \mathrm{Km}$, etc.). A concept paper emerging from the $\mathrm{K}^{*}$ conference held in Hamilton, 2012. Available: https://www.gov.uk/ dfid-research-outputs/expanding-our-understanding-of-k-kt-ke-kttkmb-kb-km-etc-a-concept-paper-emerging-from-the-k-conferenceheld-in-hamilton-ontario-canada-april-2012 [Accessed 18 Feb 2019].

31. Boshoff N. Nelius Boshoff on research uptake management. Available: http://www.drussa.org/index.php?option=com_content\& view=article\&id $=1318 \% 3$ Anelius-boshoff-on-research-uptakemanagement\&catid=206\%3Aword-of-the-moment\&ltemid=299\& lang=en [Accessed 18 Feb 2019].

32. Mendizabal E, On Think Tanks. Research uptake: what is it and can it be measured? on think tanks blog, 2013. Available: https:// onthinktanks.org/articles/research-uptake-what-is-it-and-can-it-bemeasured/

33. DFID UK. Research uptake guidance, 2016. Available: https:// www.gov.uk/government/publications/research-uptake-guidance [Accessed 18 Feb 2019].

34. Sohn J. Navigating the politics of evidence-informed policymaking: strategies of influential policy actors in Ontario. Palgrave Commun 2018;4.

35. Walley J, Khan MA, Witter S, et al. Embedded health service development and research: why and how to do it (a ten-stage guide). Health Res Policy Syst 2018;16.

36. Vindrola-Padros C, Pape T, Utley M, et al. The role of embedded research in quality improvement: a narrative review. BMJ Qual Saf 2017;26:70-80.

37. Ghaffar A, Langlois EV, Rasanathan K, et al. Strengthening health systems through embedded research. Bull World Health Organ 2017;95:87.

38. Awoonor-Williams JK, Appiah-Denkyira E. Bridging the interventionimplementation gap in primary health care delivery: the critical role of integrated implementation research. BMC Health Serv Res 2017:17(Suppl 3):772-3.

39. Walt G, Gilson L. Reforming the health sector in developing countries: the central role of policy analysis. Health Policy Plan 1994;9:353-70.

40. Gilson L, Orgill M, Shroff ZC. A health policy analysis reader: the politics of policy change in low- and middle-income countries, 2018.
Available: http://www.who.int/alliance-hpsr/resources/publications/ hpa-reader/en/ [Accessed 8 Apr 2019].

41. Mutale W, Chintu N, Amoroso C, et al. Improving health information systems for decision making across five sub-Saharan African countries: implementation strategies from the African health Initiative. BMC Health Serv Res 2013;13 Suppl 2:S9

42. HSR oral session on partnerships for research, capacity development and policy: challenges and opportunities. Liverpool; 2018.

43. Sherr K, Cuembelo F, Michel C, et al. Strengthening integrated primary health care in Sofala, Mozambique. BMC Health Serv Res 2013;13 Suppl 2:S4.

44. Fernandes $Q$, Sherr K. Presentation from the Doris Duke charitable Foundation African health Initiative (AHI) - Mozambique. In: Embedding research to strengthen health systems experiences. Liverpool, 2018.

45. Tsofa B. Researcher-Managers' Collaboration in Facilitating RealTime Research Uptake for System Strengthening: Lessons from Kilifi County, Kenya. Liverpool; 2018.

46. RESYST. Ethical challenges in conducting embedded, long-term research [Internet]. London: RESYST, 2017. Available: https://resyst. Ishtm.ac.uk/resources/ethical-challenges-in-conducting-embeddedlong-term-research [Accessed 10 Apr 2019].

47. Gilson L, Barasa E, Nxumalo N, et al. Everyday resilience in district health systems: emerging insights from the front lines in Kenya and South Africa. BMJ Glob Health 2017;2:e000224.

48. Sheikh K, Ranson MK, Gilson L. Explorations on people centredness in health systems. Health Policy Plan 2014;29 Suppl 2:ii1-5.

49. Kieny M-P, Evans DB, Schmets G, et al. Health-system resilience: reflections on the Ebola crisis in Western Africa. Bull World Health Organ 2014;92:850.

50. Vandi. Responding to the Ebola viral diseases outbreak in Sierra Leone: understanding the role and capacities of the districts. Liverpool; 2018.

51. Dixon MG, Schafer IJ, Centers for Disease Control and Prevention (CDC). Ebola viral disease outbreak--West Africa, 2014. MMWR Morb Mortal Wkly Rep 2014;63:548-51.

52. Kielmann K, Dickson-Hall L, Moshabela M. Moving towards decentralized care for drug-resistant TB in South Africa: the role of high- and low- level "tinkering" in health systems responses. Conference: 5th Global Symposium on Health Systems Research

53. Gilson L, Hanson K, Sheikh K, et al. Building the field of health policy and systems research: social science matters. PLoS Med 2011;8:e1001079.

54. HSR satellite session giving communities a voice with research evidence. Liverpool; 2018.

55. Sivic S, Huremovic A, Djerzic $H$. Social exclusion as a determining health factor of the Roma population. Med Arch 2013;67:60-2.

56. Cook B, Wayne GF, Valentine A, et al. Revisiting the evidence on health and health care disparities among the Roma: a systematic review 2003-2012. Int J Public Health 2013;58:885-911.

57. Hajioff S, McKee M. The health of the Roma people: a review of the published literature. J Epidemiol Community Health 2000;54:864-9.

58. HSR poster session on advancing a theory of change: potential of SDGs to transform contemporary realities of exclusion to realization of UHC. Liverpool; 2018.

59. HSR session on using the media to facilitate bottom up accountability, health systems responsiveness and participatory decision-making processes: the role of citizen journalists, activists and the media. Liverpool; 2018.

60. HSR session on scaling up health systems interventions. Liverpool 2018.

61. Mazengera S. Missing medicines in Malawi: Campaigning against stock-outs of essential drugs, 2012. Available: https://oxfamilibrary. openrepository.com/handle/10546/226732 [Accessed $10 \mathrm{Apr}$ 2019]. 